\title{
AKTIVITAS ANTIFUNGI EKSTRAK DAUN BELUNTAS, JAWER KOTOK, DAN SIRIH SERTA KOMBINASINYA TERHADAP Candida albicans
}

\section{ANTIFUNGAL ACTIVITY OF Pluchea indica, Coleus scutellarioides, Piper betle AND THEIR COMBINATION EXTRACTS AGAINST Candida albicans}

\author{
Umi Yuniarni, Yani Lukmayani \\ Prodi Farmasi, Fakultas Matematika dan Ilmu Pengetahuan Alam, \\ Universitas Islam Bandung, Jl.Rangga Malela No.1, Bandung 40116 \\ Email: uyuniarni@gmail.com
}

Submitted: 16-09-2015 Reviewed: 24-09-2015

Accepted: 26-04-2016

\begin{abstract}
ABSTRAK
Daun sirih, jawer kotok dan beluntas telah digunakan secara empiris untuk mengatasi keputihandan telah terbukti secara ilmiah dapat menghambat pertumbuhan Candida albicans. Penelitian ini bertujuan untuk mengevaluasi kombinasi ekstrak yang efektif sebagai antimikroba terhadap Candida albicans sebagai penyebab keputihan. Ekstrak tunggal maupun kombinasi dari dua dan tiga ekstrak dievaluasi aktivitasnya terhadap Candida albicans menggunakan metode difusi agar. Seluruh ekstrak tunggal maupun kombinasinya memberikan hambatan terhadap Candida albicans. Diameter hambat ekstrak tunggal yang paling besar diberikan oleh ekstrak daun sirih. Diameter hambat terbesar untuk kombinasi dua ekstrak ditunjukkan oleh sirih dan beluntas $(26,57 \pm 0,56 \mathrm{~mm})$ dibandingkan terhadap kombinasi 2 ekstrak lainnya yaitu sirih dan jawer kotok $(25,17 \pm 0,96 \mathrm{~mm})$; dan beluntas dan jawer kotok $(22,73 \pm 0,95 \mathrm{~mm})$. Kombinasi sirih+jawer kotok+beluntas memberikan diameter hambat sebesar 27,53 $\pm 1,10 \mathrm{~mm}$. Kombinasi ekstrak tidak memberikan diameter yang lebih baik dibandingkan terhadap ekstrak sirih tunggal.
\end{abstract}

Kata kunci: Antifungi, Candida albicans, Pluchea indica,Coleus scutellarioides, Piper betle

\begin{abstract}
Piper betle, Coleus scutellarioides and Pluchea indica have been used empirically to overcome vaginal discharge and scientifically proven to inhibit the growth of Candida albicans. The goal of this research was to search for a combined extract with effective antimicrobial activity against Candida albicans. Single extract,combination of two and three extracts evaluated antimicrobial activity against Candida albicans using agar diffusion method. Inhibitory effect of Piper betle showed the greatest activity against Candida albicans compared to other single extract. Combination of Piper betle and Pluchea indica $(26.57 \pm 0.56 \mathrm{~mm})$ gave greater inhibition than two other combination extracts (Piper betle and Coleus scutellarioides $(25.17 \pm 0.96 \mathrm{~mm})$; Coleus scutellarioides and Pluchea indica $(22.73 \pm 0.95 \mathrm{~mm})$.The combination of Piper betle, Pluchea indica and Coleus scutellarioides gave inhibition of $27.53 \pm 1.10 \mathrm{~mm}$. extracts did not give a better diameter compared to the betle extract.
\end{abstract}

Keywords: Antifungal, Candida albicans, Pluchea indica, Coleus scutellarioides, Piper betle 


\section{PENDAHULUAN}

Keputihan dapat disebabkan oleh infeksi, salah satunya adalah karena Candida albicans. Candida spp. terdistribusi secara luas di lingkungan karena merupakan bagian dari populasi komensal normal pada kulit, saluran gastrointestinal, dan saluran genitalia wanita (Gillespie dan Bamford, 2009). Sekitar 75\% wanita diperkirakan pernah mengalami satu kali episode vulvovaginal candidiasis selama hidupnya. Sekitar 10-20\% wanita tidak mengalami gejala dan menjadi carier vaginal candidiasis dan meningkat $40 \%$ selama kehamilan. Pengobatan kandidiasis dilakukan baik secara oral ataupun intravaginal menggunakan antibiotik golongan azol (Sherrad, et al., 2011). Akan tetapi efek samping yang tidak diinginkan yang umum terjadi pada terapi dengan golongan azol adalah gangguan gastrointestinal dan dapat menyebabkan abnormalitas pada enzim hati (Katzung, 2010). Sehingga dapat dipilih pengobatan tradisional sebagai alternatif. Selain itu, penggunaan obat tradisional umumnya dipilih karena faktor biaya maupun ketidaknyamanan evaluasi medis (Lodise et al., 2009). Obat tradisional yang umum digunakan untuk mengobati keputihan oleh masyarakat Indonesia diantaranya adalah daun sirih, beluntas dan jawer kotok (Dalimartha, 1999; Dalimartha, 2000; Dalimartha, 2006).

Pluchea indica digunakan secara tradisional untuk mengobati berbagai penyakit infeksi seperti gatal-gatal, infeksi pada mata dan kulit (Hussain, 2013). Untuk mengobati keputihan biasanya daun beluntas dicampur dengan herba lain direbus dan diminum airnya(Lodise et al., 2009). Secara ilmiah, minyak atsiri daun beluntas terbukti memiliki daya hambat terhadap Candida albicans pada konsentrasi $12,5 \%$. Kandungan kimia minyak atsiridaun beluntas tersebut terdiri atas caryophyllene, isocaryophyllene serta senyawa derivat azulene, dan naphthalene (Arini et al., 2006).

Daun sirih dan jawer kotok pun digunakan dengan cara direbus dan diminum airnya (Dalimartha, 1999; Dalimartha, 2000; Dalimartha, 2006).Daun sirih mengandung hydroxychavicol yang terbukti dapat menghambat pertumbuhan Candida albicans dengan mekanisme kerja diduga merusak membran sel dari Candida albicans (Ali et al., 2010).

Selain digunakan secara tunggal, masyarakat menggunakan daun sirih, beluntas dan jawer kotok secara kombinasi. Kombinasi obat umumnya diharapkan dapat meningkatkan khasiat yang diharapkan. Penggunaan ekstrak maupun minyak atsiri dari tanaman tersebut secara tunggal telah banyak dibuktikan secara ilmiah walaupun tidak terpublikasi. Namun penggunaan kombinasi tanaman tersebut belum cukup dibuktikan secara ilmiah. Penelitian ini bertujuan untuk mengevaluasi kombinasi ekstrak yang efektif sebagai antimikroba terhadap Candida albicans sebagai penyebab keputihan. Selain itu penelitian ini dilakukan untuk mengetahui efektifitas penggunaan kombinasi ekstrak dibandingkan terhadap ekstrak tunggalnya.

\section{METODE PENELITIAN}

\section{Bahan Penelitian}

Daun sirih diperoleh dari Kecamatan Sagalaherang-Subang, sedangkan simplisia jawer kotok diperoleh dari Kecamatan Kasomalang-Subang, dan simplisia beluntas diperoleh dari daerah Perkebunan Manoko - Lembang. Determinasi tanaman dilakukan di Herbarium Bandungense, Sekolah Ilmu dan Teknologi Hayati, Institut Teknologi Bandung. Material tanaman dicuci dan dikeringkan, kemudian digiling menjadi serbuk.

\section{Penyiapan ekstrak}

Ekstrak etanol dibuat dengan metode refluks selama 1 jam. Ekstrak etanol kemudian dipekatkan dengan menggunakan alat rotary evaporator.

\section{Mikroba uji}

Mikroba uji yang digunakan adalah Candida albicans (ATCC 10231) yang diperoleh dari Laboratorium Mikrobiologi, Sekolah Ilmu dan Teknologi Hayati, Institut Teknologi Bandung. 


\section{Pengujian aktivitas antimikroba}

Pengujian aktivitas antimikroba dilakukan dengan metode difusi agar Candida albicans ditransfer secara aseptik menggunakan kawat ose kedalam tabung reaksi yang berisi $5 \mathrm{~mL}$ Sabourad Dextrose Broth. Inokula kemudian ditambahkan sampai larutan setara dengan lar standar 0,5 Mc Farland. Suspensi mikroba sebanyak $1 \mathrm{~mL}$ ditambahkan ke dalam 15mL Sabourad Dextrose Agar. Agar dibiarkan 15 menit sampai menjadi padat. Permukaan agar dilubangi menggunakan perforator dengan diameter $9 \mathrm{~mm}$. Kedalam lubang dimasukkan ekstrak sesuai konsentrasi yang diinginkan sebanyak $40 \mu \mathrm{L}$. Larutan DMSO digunakan sebagai kontrol negatif dan ketokenazole $(50 \mu \mathrm{g} / \mathrm{mL})$ sebagai kontrol positif. Cawan petri diinkubasi pada suhu $25^{\circ} \mathrm{C}$ selama 24 jam, kemudian dievaluasi diameter hambatnya. Tes dilakukan sebanyak 3 kali pengulangan.

\section{Analisis Statistik}

Data penelitian ekstrak tunggal dianalisis dengan metode univariate analysis of variances dan uji lanjut dengan LSD dengan tingkat kepercayaan $95 \%$. Data penelitian ekstrak kombinasi dianalisis dengan one way analysis of variances dan uji lanjut dengan LSD dengan tingkat kepercayaan $95 \%$.

\section{HASIL DAN DISKUSI \\ Pengujian Aktivitas Ekstrak Tunggal}

Hasil pengujian ekstrak untuk masing-masing simplisia menunjukkan dengan bertambahnya konsentrasi maka daya hambat terhadap perkembangan jamur Candida albicans, sebagai penyebab keputihan, juga bertambah besar. Bila dibandingkan dari ketiga simplisia tersebut maka daun sirih memiliki potensi antijamur yang paling besar berdasarkan daya hambat yang ditimbulkannya.

Tabel I. Hasil pengujian aktivitas antijamur ekstrak sirih, beluntas dan jawer kotok

\begin{tabular}{cccc}
\hline \multirow{2}{*}{ Konsentrasi Ekstrak (\%) } & \multicolumn{3}{c}{ Rata-Rata Diameter Hambat $(\mathbf{m m}) \pm$ SD } \\
\cline { 2 - 4 } & Sirih & Beluntas & Jawer Kotok \\
\hline 75 & $31,33 \pm 1,08$ & $20,33 \pm 0,87$ & $23,47 \pm 1,20$ \\
50 & $29,90 \pm 1,67$ & $19,33 \pm 0,50$ & $22,60 \pm 0,56$ \\
25 & $27,43 \pm 0,59$ & $17,67 \pm 0,74$ & $21,33 \pm 0,83$ \\
\hline
\end{tabular}

Keterangan : jumlah pengulangan sebanyak 3 kali. $\mathrm{SD}=$ standar deviasi, keokenazole $0,05 \%$ digunakan sebagai kontrol dengan diameter hambat $18,33 \mathrm{~mm}$.

Analisis statistik menunjukkan bahwa semakin tinggi konsentrasi maka diameter hambat pun semakin meningkat (nilai Sig 0,000). Daun sirih menunjukkan aktivitas paling besar dibandingkan terhadap beluntas (nilai Sig 0,000) dan jawer kotok (nilai Sig 0,000). Aktivitas antijamur jawer kotok lebih besar dibandingkan daun beluntas (nilai Sig 0,000) .

\section{Pengujian Aktivitas Ekstrak Kombinasi}

Kombinasi dua ekstrak terdiri atas ekstrak konsentrasi $25 \%$ w/v yang dicampurkan dengan perbandingan 1:1. Kombinasi tiga ekstrak terdiri atas konsentrasi $25 \% \mathrm{w} / \mathrm{v}$ yang dicampurkan dengan perbandingan 1:1:1. Analisis statistik kombinasi 2 ekstrak disbandingkan terhadap ekstrak tunggal 50\%, sedangkan kombinasi 3 ekstrak dibandingkan terhadap ekstrak tunggal $75 \%$.

Hasil analisis anova menunjukkan nilai signifikansi sebesar $0.000<0,05$ artinya perbedaan perlakuan memberikan pengaruh diameter hambat yang berbeda. Untuk mengetahui apakah kombinasi ekstrak menghasilkan aktivitas antijamur yang lebih baik dibandingkan terhadap ekstrak tunggal, maka dilakukan uji lanjut LSD. Hasil uji lanjut dapat dilihat pada Tabel III.

Hasil uji lanjut LSD menunjukkan bahwa kombinasi sirih+jawer kotok memberikan aktivitas yang kurang baik dibandingkan ekstrak sirih 50\% (nilai Sig 0.000) tetapi lebih baik dari jawer kotok $50 \%$ (nilai Sig 0,006). Kombinasi sirih+beluntas menunjukkan aktivitas yang kurang baik dibandingkan ekstrak sirih 50\% (nilai Sig 0.001) tetapi lebih baik dari beluntas 50\% (nilai Sig 0,000). Kombinasi jawer kotok+beluntas menunjukkan aktivitas yang relatif sama dengan jawerkotok 50\% (nilai Sig 0.874) tetapi lebih baik bila dibandingkan ekstrak beluntas 50\% (nilai Sig 0.001).Kombinasi 
sirih+jawerkotok+beluntas memberikan aktivitas antijamur yang kurang baik dibandingkan ekstrak tunggal sirih (nilai Sig 0,000) tetapi lebih baik dibandingkan dengan beluntas dan jawer kotok tunggal konsentrasi $75 \%$ (nilai Sig 0,000).

Kombinasi ekstrak memberikan diameter hambat yang lebih kecil dibandingkan dengan ekstrak sirih tunggal yang signifikan secara statistik. Hal ini menunjukkan bahwa kombinasi ekstrak tidak memberikan efek sinergis yang diharapkan. Maka penggunaan kombinasi ekstrak sirih, jawer kotok dan beluntas secara empiris sebenarnya tidak seefektif penggunaan daun sirih tunggal untuk mengatasi keputihan yang diakibatkan oleh Candida albicans. Daun sirih lebih baik digunakan secara tunggal untuk mengatasi keputihan karena Candida albicans.

Tabel II. Hasil pengujian aktivitas anti jamur kombinasi ekstrak sirih, jawer kotok dan beluntas

\begin{tabular}{cc}
\hline Ekstrak & Rata-rata diameter hambat $(\mathbf{m m}) \pm$ SD \\
\hline Sirih + Jawer kotok & $25,17 \pm 0,96$ \\
Sirih + Beluntas & $26,57 \pm 0,56$ \\
Jawerkotok + Beluntas & $22,73 \pm 0,95$ \\
Sirih 50\% & $29,70 \pm 1,75$ \\
Beluntas 50\% & $19,33 \pm 0,50$ \\
Jawer kotok 50\% & $22,60 \pm 0,56$ \\
Sirih +jawer+beluntas & $27,53 \pm 1,10$ \\
Sirih 75\% & $31,33 \pm 1,08$ \\
Beluntas 75\% & $20,33 \pm 0,87$ \\
Jawer kotok 75\% & $23,47 \pm 1,21$ \\
\hline
\end{tabular}

Keterangan : jumlah pengulangan sebanyak 3 kali. SD=standar deviasi, keokenazole 0,05\% digunakan sebagai kontrol dengan diameter hambat $18,33 \mathrm{~mm}$.

\begin{tabular}{ccccc}
$\begin{array}{c}\text { Tabel III. Hasil analisis statistik uji lanjut LSD kombinasi ekstrak dibandingkan terhadap } \\
\text { ekstrak tunggal }\end{array}$ \\
$\begin{array}{c}\text { Diameter Hambat } \\
\text { Ekstrak Kombinasi }\end{array}$ & $\begin{array}{c}\text { Diameter Hambat } \\
\text { Ekstrak Tunggal }\end{array}$ & Signifikani \\
\hline \multirow{2}{*}{ Sirih + Jawer kotok } & $25,17 \pm 0,96$ & Sirih & $29,70 \pm 1,75$ & $0,000^{*}$ \\
& & Jawer kotok & $22,60 \pm 0,56$ & $0,006^{*}$ \\
Sirih+ Beluntas & \multirow{2}{*}{$26,57 \pm 0,56$} & Sirih & $29,70 \pm 1,75$ & $0,001^{*}$ \\
& \multirow{2}{*}{$22,73 \pm 0,95$} & Beluntas & $19,33 \pm 0,50$ & $0,000^{*}$ \\
Jawer kotok + Beluntas & Jawer kotok & $22,60 \pm 0,56$ & 0,874 \\
& Beluntas & $19,33 \pm 0,50$ & $0,001^{*}$ \\
Sirih + & \multirow{3}{*}{$27,53 \pm 1,10$} & Sirih & $31,33 \pm 1,08$ & $0,000^{*}$ \\
Jawer kotok + Beluntas & Beluntas & $20,33 \pm 0,87$ & $0,000^{*}$ \\
& & Jawer kotok & $23,47 \pm 1,21$ & $0,000^{*}$ \\
\hline
\end{tabular}

\section{KESIMPULAN}

Seluruh ekstrak tunggal maupun kombinasinya memberikan hambatan terhadap Candida albicans. Kombinasi ekstrak pada penelitian ini tidak menunjukkan diameter hambat yang lebih besar dibandingkan diameter hambat yang lebih besar dibandingkan diameter hambat ekstrak daun sirih.

\section{DAFTAR PUSTAKA}

Ali I, Khan FG, Suri KA, Gupta BD, Satti NK, Dutt P, Afrin F, Qazi GN, Khan IA. In vitro antifungal activity of hydroxychavicol isolated from Piper betle L. Annals of Clinical Microbiology and Antimicrobials ; 9(7):1-9.

Arini S, Nurmawan D, Alfiani F, Mulyani S. 2006. Uji Aktivitas Antifungi Minyak Atsiri Daun Beluntas Terhadap Candida Albicans Dan Pembuatan Sediaan Yang Sesuai. Jurnal Farmasi Indonesia;3(2):84-88. 
Dalimartha S. 1999. Atlas Tumbuhan Obat Indonesia Jilid 1.1st ed.Jakarta: Trubus Agriwidya; p.1821.

Dalimartha S. 2000. Atlas Tumbuhan Obat Indonesia Jilid 2. 8th ed. Jakarta: Trubus Agriwidya; p. 6570.

Dalimartha S. 2006. Atlas Tumbuhan Obat Indonesia Jilid 4. 1st ed. Jakarta: Puspa Swara; p. 87.

Gillespie S.H., and Bamford K.B. 2009. Mikrobiologi Medis dan Infeksi. 3rd ed. Alih bahasa: dr. Stella Tinia. Jakarta: Penerbit Erlangga; p.80.

Hussain H, Al-Harrasi A, Abbas G, Rehman NU, Mabood F, Ahmed I, Saleem M, Van Ree T, Green IR, Anwar S, Badshah A, Shah A, Ali I. The Genus Pluchea :Phytochemistry,Traditional Uses, and Biological Activities. Chemistry and Biodiversity;10:1944-1971.

Katzung,B.G.2010. Farmakologi Dasar dan Klinik, EGC, Jakarta. p.119.

Lodise NM and Shimp AL. 2009. Vaginal and Vulvoginal Disorder. In: Young LL, editor. Handbook of Nonprescription Drugs: An Interactive Approach to Self-Care. Washington DC: American Pharmacist Association; p. 117-36.

Sherrard J, Donders G, White D. 2011. European Guideline on the Management of Vaginal Discharge. WHO.p.5 
